\title{
A method for the highly accurate quantification of gas streams by on-line chromatography
}

\author{
Víctor Stivenson Sandoval-Bohorquez ${ }^{1}$, Edwing Alexander Velasco Rozo ${ }^{1}$, Víctor Gabriel Baldovino- \\ Medrano ${ }^{1,2, *}$ (D. \\ ${ }^{1}$ Centro de Investigaciones en Catálisis (CICAT), Escuela de Ingeniería Química, Universidad Industrial de Santander, Parque Tecnológico \\ de Guatiguará, Km 2 vía El Refugio, Piedecuesta, Santander 681011, Colombia. \\ ${ }^{2}$ Laboratorio de Ciencia de Superficies (SurfLab), Universidad Industrial de Santander, Parque Tecnológico de Guatiguará, Km 2 vía El \\ Refugio, Piedecuesta, Santander 681011, Colombia. \\ *Corresponding author. Tel. +54 6344000 ext. 1485. E-mail: vicbaldo@uis.edu.co. ORCID: http://orcid.org/0000-0003-3227-0251. Twit- \\ ter: @ vigabalme
}

\begin{abstract}
Quantification of the gas streams from chemical systems such as catalytic reactors are routinely performed by on-line chromatography. Gas chromatographs used for this purpose are typically provided with a combination of thermal conductivity (TCD) and flame ionization (FID) detectors to be able to detect and quantify both permanent gases and hydrocarbons. However, the accuracy of the quantification is hindered by the intrinsic limitations of each type of detector. Namely, TCD has low sensitivity and FID does not detect permanent gases; $\mathrm{CO}_{\mathrm{x}}, \mathrm{N}_{2}, \mathrm{H}_{2}$, etc. Therefore, modern gas chromatographs include methanizer units to partially overcome this shortcoming by converting $\mathrm{CO}_{\mathrm{x}}$ to methane. However, as far as these authors know, the literature has not presented an analytical method to characterize gas streams with high accuracy by the simultaneous use of a combination of a TCD-FID detection system provided with a methanizer. In this work, we developed analytical methods for this purpose. Our approach consisted on formulating a mathematical model for the well-known external and internal standard quantification methods in gas chromatography. We specifically applied the methodology to the analysis of the gas streams from a catalytic reactor performing the combustion of methane. We found that the commonly applied external standard method leads not only to inaccurate quantification but also to physically meaningless conclusions on the behavior of the selected model system. In contrast, the internal standard method led to a highly accurate quantification with a physical meaning. Considering these findings, our contribution also draws attention to the need for a thoughtful application of chromatographic methods when studying the reactivity of gas systems.
\end{abstract}

\section{INTRODUCTION}

On-line chromatography is the most used technique to quantitatively characterize the gaseous streams from chemical reactors and certain unit operations. ${ }^{1-3}$ By "on-line," it is implied that the gas chromatograph (GC) is connected to the outlet stream of the corresponding process unit. The gaseous samples must be introduced into the GC by intricate arrangements of valves. Fig. 1 sketches a basic six-way valve system that allows the automatic injection of the samples into the instrument. In a typical run, the outlet gas stream from the given process continuously passes through a loop, placed in the injection port of the chromatograph, and discharges in a vent (Fig. 1 top). When a sample is to be analyzed, the valve is switched to a position in which the gas flowing by the loop is injected to the GC by passing the carrier gas of the instrument through the loop in order to carry the analyte into the chromatograph (Fig. 1 bottom). In most conventional on-line GC systems, the atmospheric conditions, namely, temperature and pressure, can affect the quantity of analyte collected by the loop to a degree where reproducibility between runs becomes a stringent constraint of the analysis. ${ }^{4}$ To correct this issue, internal standards are added to the gaseous samples during each sample injection. ${ }^{2}$; alternatively, some researchers have opted for implementing statistical methods for assessing the uncertainty in the quantity of analyte that is injected in the runs of their on-line GC systems. ${ }^{4,5}$ After accomplishing the automatized injection of the sample, the carrier gas carries the analyte through the separation columns, where each gaseous compound is partially retained and separated and further eluted before reaching the detection system of the instrument.

Most on-line GC detection systems used for the analysis of gaseous streams from hydrocarbon or biomass related processes are typically configured with one or several detectors such as: i) one Thermal Conductivity Detector (TCD) able to detect gaseous compounds as a function of their differences in thermal conductivity and whose concentration is higher than $~ 100 \mathrm{ppm}$; ii) one Flame Ionization Detector (FID) that detects hydrocarbons in concentrations higher than $\sim 0.5 \mathrm{ppm}$, but cannot detect

permanent gases like $\mathrm{O}_{2}, \mathrm{~N}_{2}, \mathrm{CO}, \mathrm{CO}_{2}$, and $\mathrm{H}_{2} \mathrm{O}{ }^{2}$ Due to this limitation, most GC systems are provided by iii) a serial TCDFID arrangement that allows detecting permanent gases with the TCD and hydrocarbons with the FID; and iv) TCDmethanizer-FID arrangements that allow detecting concentrations of $\mathrm{CO}_{2}$ and $\mathrm{CO}$ below the 10ppm limit of the TCD, by hydrogenating $\mathrm{CO}_{2}$ and $\mathrm{CO}$ to methane after passing a fraction of the analyte through a small catalytic reactor; called the 
methanizer, and further submitting the outlet of the methanizer to the FID. ${ }^{6}$ Despite the implementation of TCD-methanizerFID arrangements, on-line GC systems still have other drawbacks when aiming to make a complete characterization of a gaseous stream containing both hydrocarbons and non-hydrocarbon gases.

On-line GC systems are fundamental for the study and monitoring of gaseous catalytic reaction units. Within this context, very accurate and reliable quantification of the concentration of each reactant is a must when assessing the performance of either the reaction unit or of the catalyst itself. Within this context, achieving closed mass balances from the input and output gaseous streams of the reaction systems is a necessary condition for process design and monitoring. Mass balances must be calculated from the relative concentrations quantified by the TCD and FID detectors of the on-line GC. However, such a task can be challenging up to a point where many process operators and even researchers either consider it helpless or tend to ignore it. The problem of achieving closed mass balances is associated with the inherent limitations of each type of detector as described before and with the fact that one needs to devise a reliable method for relating the concentrations of the different compounds from more than one detector at the same time.

Fig. 1. Scheme of the injection mechanism in on-line gas chromatography, in the normal position (top) and the injection position (bottom).
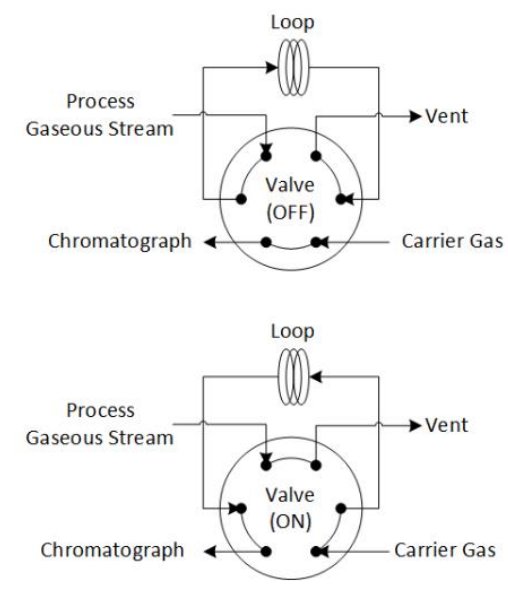

As particular examples of the hurdles of measuring concentrations and closing mass balances from data read from more than one detector in an on-line GC, we may cite processes in which relatively simple reactions such as the total (Eq. 1) or partial (Eq. 2) combustion of methane, and the reforming of methane with carbon dioxide, a.k.a. dry reforming, (Eq. 3), must be followed by on-line GC.

$$
\begin{aligned}
& \mathrm{CH}_{4}+2 \mathrm{O}_{2} \rightarrow \mathrm{CO}_{2}+2 \mathrm{H}_{2} \mathrm{O} \\
& \mathrm{CH}_{4}+\frac{3}{2} \mathrm{O}_{2} \rightarrow \mathrm{CO}+2 \mathrm{H}_{2} \mathrm{O} \\
& \mathrm{CH}_{4}+\mathrm{CO}_{2} \rightarrow 2 \mathrm{CO}+2 \mathrm{H}_{2}
\end{aligned}
$$

To do so, the instrument must be at least provided with both one TCD and one FID since the outlet gas stream is composed by $\mathrm{CH}_{4}, \mathrm{O}_{2}, \mathrm{H}_{2}, \mathrm{CO}_{2}, \mathrm{CO}$, and $\mathrm{H}_{2} \mathrm{O} .^{7-10}$ These reactions are traditionally studied as alternatives for the abatement or valorization of methane which is a 21 times more potent greenhouse gas than carbon dioxide. ${ }^{11-13}$ At the research level, many scientists devote efforts towards the development of low-cost stable catalysts able to activate methane at the lowest possible temperature. ${ }^{11,12,14-17}$ For this purpose, the studies are most often carried out in fixed bed catalytic micro-reactors whose output is monitored by on-line GC with input streams whose composition is about $0.1-10$ vol. $\%$ of methane, $2-50$ vol. $\%$ oxygen diluted in nitrogen, argon or helium. ${ }^{11}$ Let us consider the lower concentration of reactants and assume $80 \%$ conversion of methane to $\mathrm{CO}_{2}$ (Eq. 1), and $10 \%$ conversion to $\mathrm{CO}$ (Eq. 2); the output stream would be composed for $\sim 100 \mathrm{ppm} \mathrm{CH}_{4}, \sim 800 \mathrm{ppm} \mathrm{CO}_{2}$, and $\sim 100 \mathrm{ppm}$ CO. If only a TCD is employed for quantification, the results would be $100 \%$ conversion of methane to $\mathrm{CO}_{2}$, i.e., an overestimation of $10 \%$ in conversion and selectivity, which is due to such hydrocarbon together the $\mathrm{CO}$ are in concentrations hardly detected by the TCD.

For the above, it is usually preferred a GC with at least a serial TCD-FID arrangement for detection. However, most investigators report quantification either by only the TCD or the FID or from an uncorrelated combination of both detectors. Furthermore, they seldom neither report statistics on the reliability of their measurements nor the mass balances for the analyzed gaseous streams of their catalytic set-ups. ${ }^{18-22}$ Besides the complications inherent to handle quantification with more than one detector, on-line GC analyses of the products from these reaction systems is complicated by the selection of an adequate internal standard. For example, the internal standard to be added must be more stable than the reactants under the usually harsh reaction conditions employed to test the catalysts. ${ }^{23,24}$ Consequently, only gases such as $\mathrm{N}_{2}, \mathrm{He}$, and Ar are suitable as internal standards for methane combustion and dry reforming. However, none of these gases is detected by the FID hence hampering the analysis of the fluctuations in the amount of analyte injected after taken each sample. Under such circumstances, the analysis must rely on the response from the TCD even if the GC is also provided with a methanizer. As already mentioned, a TCD is two orders of magnitude less sensible as compared to an FID; hence relying solely on the former also harms product quantification.

This contribution presents an alternative method for quantifying the composition of gaseous streams by on-line GC. Particularly, we successfully implemented a method that, using $\mathrm{N}_{2}$ as an internal standard, allows correlating the responses from a serial TCD-FID arrangement for compounds quantification while checking for mass balance closure during the analysis of the gaseous effluents from a catalytic reactor. As an example, we show how this method was implemented to monitor the effluents from a lab-scale reaction set-up performing the catalytic combustion of methane. The mathematical deduction of a parameter called sensitivity factor allowed for the combined use of both the signals from the TCD and the FID for quantification despite their strong differences in sensibility. In general, the developed method can be applied to the on-line GC monitoring of any gaseous stream. 


\section{ANALYSIS OF THE PERFORMANCE OF CATALYTIC SYSTEMS FROM THE GC QUANTIFICATION OF GASEOUS STREAMS}

Before presenting the mathematical fundamentals of the method, we detail how the performance of catalytic systems is assessed by GC quantification of gas effluents.

According to IUPAC recommendations, ${ }^{25}$ the catalytic performance of a catalytic system can be assessed by calculating the conversion of reactants $\left(X_{\mathrm{r}}\right)$ and the selectivity toward the products from the reaction. For continuous reactors; which are those most often monitored by on-line GC, the conversion of reactants is calculated in terms of the molar flow of the feed (reactants) that inlet $\left(F_{r}^{0}\right)$ and outlet $\left(F_{r}\right)$ the reactor following Eq. 4. Conversion is thus defined as a parameter that describes the fraction of a given reactant that is chemically converted into a given product. Therefore, conversion is the first metric for analyzing the catalytic activity of a given material. On the other hand, the selectivity to any given reaction product $\left(S_{p}\right)$ is calculated as a function of the molar flow of products detected at the inlet $\left(F_{p}^{0}\right)$ and outlet $\left(F_{p}\right)$ of the reactor multiplied by the ratio between the stoichiometric coefficients of the reactants and products $(v)$, as shown in Eq. 5. Selectivity is a critical metric for the assessment of the catalytic properties of a material since it is directly related to the cost-benefit ratio of the process.

$$
\begin{gathered}
X_{r}=\frac{F_{r}^{0}-F_{r}}{F_{r}^{0}} \\
S_{p}=v \frac{F_{p}-F_{p}^{0}}{F_{r}^{0}-F_{r}}
\end{gathered}
$$

Within this context, the challenge when quantifying conversion and selectivity by on-line GC thus consists of measuring the molar flow of all species that participate in the reaction as a function of the detector signal with the highest precision possible.

There are two possible methods for a high accurate quantification of molar flows with GC. They are the so called external and internal standard methods.

\subsection{External standard method}

In the case of chromatographic analysis, the concentration of the $\mathrm{i}$-th compound (reactant, $\mathrm{r}$, or product, $\mathrm{p}$ ) in a gaseous sample (e.g., the ratio between the molar flow of the i-th compound, $F_{i}$, and the total molar flow, $F_{T}$ ) can be related to the area of its peak $\left(A_{i}\right)$ in the corresponding chromatogram by way of a proportionality constant named response factor $\left(\gamma_{\mathrm{i}}\right)$, as shown in Eq. 6. The value of this constant must be calculated for each species by a calibration curve obtained from plotting different known molar flows and their respective signal. By replacing the Eq. 6 in Eqs. 4 and 5, and assuming that the total molar flow is constant $\left(F_{T}^{0}=F_{T}\right)$, the conversion and selectivity in terms of the chromatograph response can be obtained as shown in Eq. 7 and 8 . By correlating the $F_{i} / F_{T}$ ratio with the chromatographic peak areas, the fluctuations of the gas flows, mostly caused by the contraction of the gases due to thermal gradients, can be normalized.

$$
\begin{gathered}
\frac{F_{i}}{F_{T}}=\gamma_{i} * A_{i}(6) \\
X_{r}=\frac{A_{r}^{0}-A_{r}}{A_{r}^{0}} \\
S_{p}=v \frac{\gamma_{p}}{\gamma_{r}} \frac{A_{p}}{\left(A_{r}^{0}-A_{r}\right)}
\end{gathered}
$$

Closure of the mass balance in the reaction system allows validating the calculated conversion and selectivity. Herein, we defined mass balances, $B_{z}$, as the ratio between the total mass of the atomic species z (i.e., carbon, oxygen or hydrogen) at the outlet and the inlet of the reactor, as shown in Eq. 9.

$$
B_{Z}=\frac{\sum_{i}\left(\gamma_{i} A_{i} N_{Z, i}\right)}{\sum_{i}\left(\gamma_{i} A_{i}^{0} N_{Z, i}\right)}
$$

Where, $N_{Z, i}$ is the number of atoms of the $\mathrm{z}$ species present in compound i-th.

\subsection{Internal standard method}

The methodology featured in the precedent section is commonly known as the external standard method. One of the problems of this method is the change in the total molar flow of gas stream after passage through the catalytic reactor. Under such circumstances, the installation of a detection system able to measure the $F_{T}^{0}$ and $F_{T}$ molar flows would be a must. Another problem is that the natural fluctuations of the atmospheric conditions (pressure, $P$, and temperature, $T$ ) can vary the total amount of injected moles $\left(n_{T}\right)$ into the GC, although the instrument has an injection loop of constant volume $\left(V_{\text {loop }}\right)$, see Eq. 10. Because of this, variations of the recorded peak areas which are due to random errors, introduce uncertainty in the quantification.

$$
n_{T}=\frac{P V_{\text {loop }}}{R T}(10)
$$

A means to control the fluctuations in both the total amount of moles injected by the loop of the GC and the total molar flow of the gaseous stream is to add an internal standard. Therefore, Eq. 6 is modified as shown in Eq. 11. In this case, the ratio between $A_{i}$ and the chromatographic peak area for the standard $\left(A_{s}\right)$ can be related to the ratio between $F_{i}$ and the respective molar flow of the standard $\left(F_{S}\right)$, using a response factor $\left(\beta_{i}\right)$. This normalization procedure counteracts the fluctuations in the amount of sample injected to the GC.

$$
\frac{F_{i}}{F_{S}}=\beta_{i} * \frac{A_{i}}{A_{s}}
$$

For the method to be successful, the standard must remain inert under the reaction conditions employed in the corresponding catalytic tests. If this condition is fulfilled, the molar flow of the standard is constant. Therefore, using the internal standard method, we can calculate the conversion of the reactants with Eq. 12, which is obtained by replacing Eq. 11 into Eq. 4 and making $\omega=A_{s}^{0} / A_{s}$. Likewise, the selectivity, Eq. 13, is calculated by replacing Eq. 11 into Eq. 5 while the mass balance can be calculated with Eq. 14 .

$$
X_{r}=\frac{A_{r}^{0}-A_{r} \omega}{A_{r}^{0}}
$$




$$
\begin{aligned}
& S_{p}=v \frac{\beta_{p}}{\beta_{r}} \frac{A_{p} \omega}{\left(A_{r}^{0}-A_{r} \omega\right)} \\
& B_{z}=\frac{\omega \sum_{i}^{n}\left(\beta_{i} A_{i} N_{Z, i}\right)}{\sum_{i}^{n}\left(\beta_{i} A_{i}^{0} N_{Z, i}\right)}
\end{aligned}
$$

\section{EXPERIMENTAL}

\subsection{Catalytic tests}

The GC quantification of the gaseous streams from a catalytic reactor for the combustion of methane was used to test the analytical methods presented herein. The catalytic tests were carried out in a continuous flow fixed bed reactor made of stainless steel with an inner diameter of $10.4 \mathrm{~mm}$. The bed was made of $100 \mathrm{mg}$ of $\mathrm{MnO}_{2}$, supplied by Erachem Comilog (LOT 622), ${ }^{26}$ diluted with $500 \mathrm{mg}$ of $\mathrm{SiO}_{2}$, both with a particle size of 75-180 $\mu \mathrm{m}$. The amount of diluent and the bed particle size were selected in order to satisfy the criteria presented in Table 1. Plugs made of quartz wool were placed before and after the catalytic bed to ensure isothermal conditions and plug flow.

Table 1. Analytical criteria used to reduce intra-reactor limitations. $L$ is the length of the bed, $d_{p}$ is the particle diameter, $d_{t}$ is the internal diameter of the tube, $b_{\max }$ is the maximum volumetric dilution ratio (inert volume/total volume of solids), $\Delta x_{r e l}$ is the acceptable relative deviation of the conversion (e.g., $0.05)$, and $x_{\text {dil }}$ is the conversion obtained with the diluted bed. ${ }^{27}$

\begin{tabular}{|c|c|}
\hline Criteria & Expression \\
\hline Negligible axial dispersion & $\frac{L}{d_{p}}>20-50$ \\
\hline Negligible radial dispersion & $\frac{d_{t}}{d_{p}}>8-10$ \\
\hline Maximum volumetric dilution of the bed & $b_{\text {max }}=\frac{\Delta x_{\text {rel }}}{\Delta x_{\text {rel }}+0.5 x_{d i l} \frac{d_{p}}{L}}$ \\
\hline
\end{tabular}

The reaction feed was a mixture of 7.7 vol. $\%$ of methane and 15.4 vol. $\%$ of oxygen diluted in nitrogen. The space velocity was $78000 \mathrm{~mL} \mathrm{~g}^{-1} \mathrm{~min}^{-1}$. We used mass flow controllers (MFC, Alicat Scientific) with an accuracy of $\pm 0.1 \%$ of full scale to feed the reactor. The outlet pressure of the reaction system was set at $110.3 \mathrm{kPa}$ using a back-pressure controller (PC, Alicat Scientific) with an accuracy of $\pm 0.3 \%$ of full scale. The catalytic reactor was heated to the reaction temperature, $500{ }^{\circ} \mathrm{C}$, by placing it inside a concentric tubular furnace controlled by a programmable logic controller (PLC, Rockwell Automation) with a heating ramp of $5^{\circ} \mathrm{C} \mathrm{min}^{-1}$. The temperature of the catalytic bed was measured by inserting a Type $\mathrm{K}$ thermocouple provided with stainless steel sheath and an external diameter of $3.2 \mathrm{~mm}$ in the middle of it. Before the tests, the catalyst was dried at $120{ }^{\circ} \mathrm{C}$ with a flow of $100 \mathrm{~mL} \mathrm{~min}^{-1}$ of $\mathrm{N}_{2}$ for $1 \mathrm{~h}$. Fig 2 shows a scheme of the reaction system.

Fig. 2. Schematic representation of the reaction system. MFC: mass flow controller; PC: pressure controller; PLC: programmable logic controller; GC: gas chromatograph.

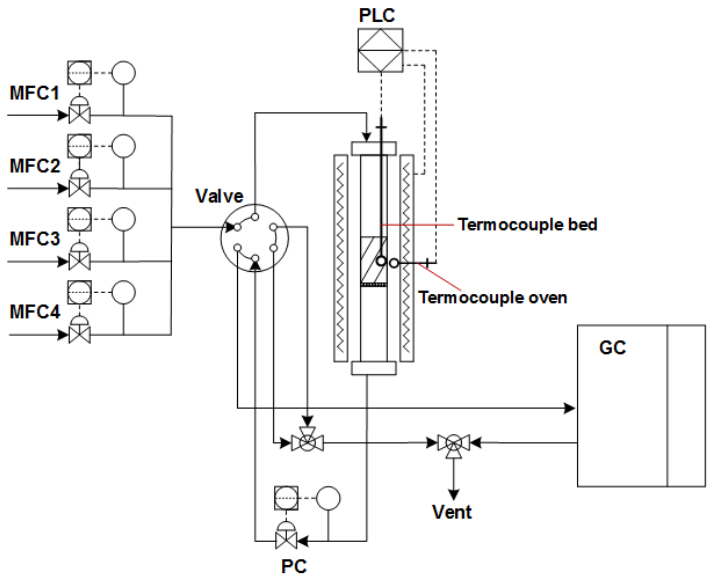

The feed and reaction products were analyzed by on-line chromatography using a GC-2014 instrument (Shimadzu Corporation). The internal configuration of the detectors and the set of packed columns used for the chromatographic analyses is presented in Fig. 3. The reactor outlet gases flowed continuously during the reaction by the $1 \mathrm{~mL}$ chromatograph injection loop. Every so often, the ten-way valve named valve 1 (Valco Instruments) switched its position to inject the sample from the gas stream of the reactor passing by the loop. Simultaneously, the carrier gas, argon, $20 \mathrm{~mL} \mathrm{~min}^{-1}$, flowed through the loop and carried the sample to column 1 (80/100 Hayesep N, $1.5 \mathrm{~m} \times 2.1$ $\mathrm{mm}$ ID) where heavy hydrocarbons and water were retained and evacuated by backflushing. The remaining gases passed to column 2 (80/100 Hayesep Q, $3 \mathrm{~m} \times 2.1 \mathrm{~mm}$ ID) that retains $\mathrm{CH}_{4}$ and $\mathrm{CO}_{2}$, and then sent to the detectors by changing the position of the six-way valve (valve 2, Valco Instruments). The lighter gases: $\mathrm{O}_{2}, \mathrm{~N}_{2}, \mathrm{H}_{2}$, and $\mathrm{CO}$ flowed to column 3 (60/80 Molecular Sieve $5 \mathrm{~A}, 3 \mathrm{~m} \times 2.1 \mathrm{~mm}$ ID) for further separation and subsequent detection. Table 2 summarizes the position of the valves during a typical GC run, and Fig 4 shows a tipically recorded chromatogram from a catalytic run.

Table 2. Summary of valve position during the GC analysis.

\begin{tabular}{|c|c|c|}
\hline \multirow{2}{*}{ Time (min) } & \multicolumn{2}{|c|}{ Position } \\
\cline { 2 - 3 } & Valve 1 & Valve 2 \\
\hline 0.0 & OFF & OFF \\
\hline 0.1 & ON & OFF \\
\hline 3.0 & OFF & OFF \\
\hline 3.5 & OFF \\
\hline 7.5 & OFF & OFF \\
\hline
\end{tabular}

The temperature of the oven of the GC was kept constant at 100 ${ }^{\circ} \mathrm{C}$. A TCD and an FID connected in series were used for measurements. The TCD was heated at $160{ }^{\circ} \mathrm{C}$ using argon as a reference gas $\left(20 \mathrm{~mL} \mathrm{~min}^{-1}\right)$. The FID was operated at $200{ }^{\circ} \mathrm{C}$ and fed with hydrogen $\left(45 \mathrm{~mL} \mathrm{~min}^{-1}\right)$ and air $\left(400 \mathrm{~mL} \mathrm{~min}^{-1}\right)$. Before entering the FID, the gaseous analytes passed through a methanizer formed by a catalytic bed of metallic Ni. The methanizer converts $\mathrm{CO}$ and $\mathrm{CO}_{2}$ into methane (according to Eqs. 15 and 16) at $375^{\circ} \mathrm{C}$, hence allowing the indirect quantification of the former with the methane signal detected in the FID. The TCD-methanizer-FID configuration was implemented to validate the measurements of $\mathrm{CO}$ and $\mathrm{CO}_{2}$ in the TCD detector. 


$$
\begin{gathered}
\mathrm{CO}_{2}+4 \mathrm{H}_{2} \rightarrow \mathrm{CH}_{4}+2 \mathrm{H}_{2} \mathrm{O} \\
\mathrm{CO}+3 \mathrm{H}_{2} \rightarrow \mathrm{CH}_{4}+\mathrm{H}_{2} \mathrm{O}
\end{gathered}
$$

Fig. 3. Schematic representation of the GC-2014 instrument used in this work. The instrument has a serial TCD-methanizerFID system.

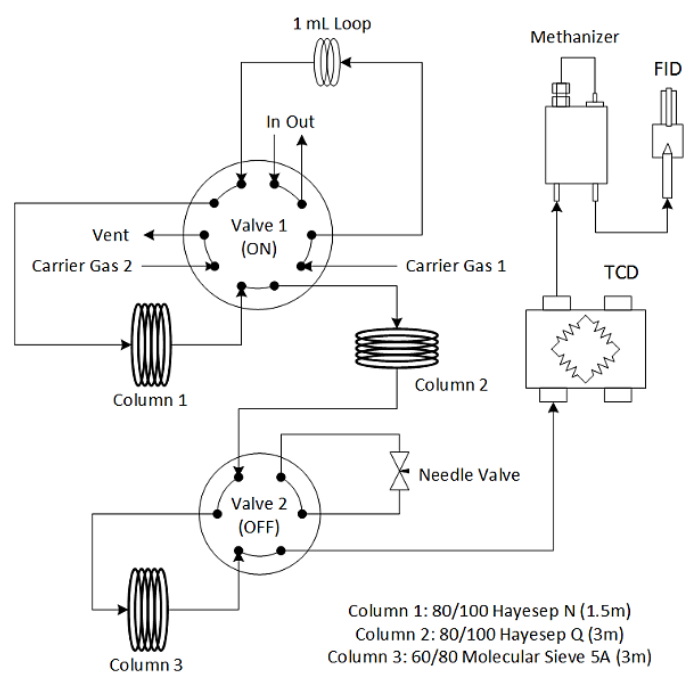

Fig. 4. Chromatograms collected for the FID (green) and TCD (blue) in the analysis of $\mathrm{CH}_{4}$ combustion products. Dashed vertical lines indicate switching in the position of the valves.

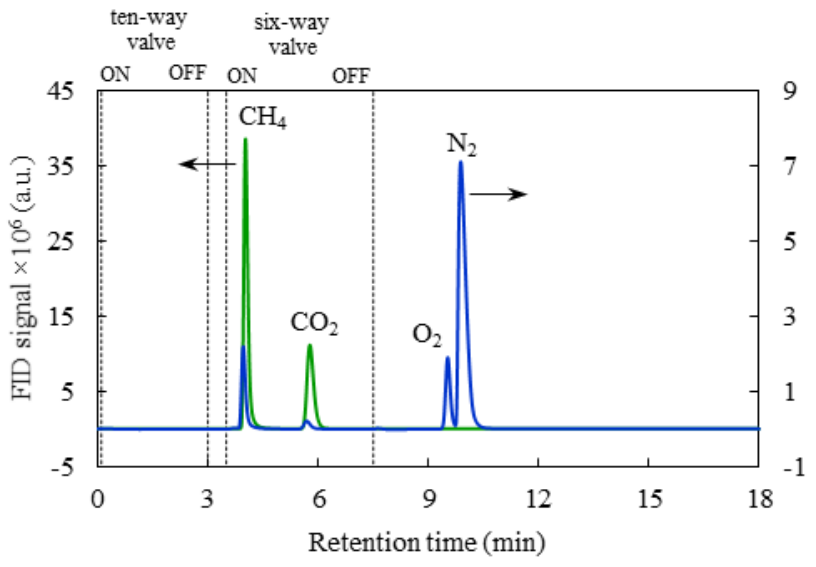

\subsection{Catalyst activity calculation by different configurations of the detection system}

The expressions developed previously for calculating the conversion, selectivity, and the mass balances were adjusted considering three configurations of the detection system: TCD, TCD-FID, TCD-Methanizer-FID, as is shown in Table 3. Only for the TCD, we rewrote equations 7-9 and 12-14 as a function

of the areas of the signals read with the TCD $\left(A_{i, T C D}\right)$. For the TCD-FID system, the term $A_{i, T C D}$ from the equations developed for the single TCD was put as a function of $A_{i, F I D}$, hence allowing to integrate the signal from the FID. In this last case, we postulated the hypothesis that the signals from the FID $\left(A_{i, F I D}\right)$ and the TCD $\left(A_{i, T C D}\right)$ are proportional given that there is no flow split between the TCD and the FID. Such a proportionality was expressed by a coefficient named sensitivity factor $\left(\alpha_{\mathrm{i}}\right)$, as it is described by Eq. 17. $\alpha_{\mathrm{i}}$ can be calculated after comparing the TCD and FID peak areas of an i-th compound from different molar flows. For the TCD-FID system, $\alpha_{\mathrm{i}}$ was calculated for $\mathrm{CH}_{4}$, whereas for the TCD-methanizer-FID configuration, $\alpha_{\mathrm{i}}$ can also be calculated for $\mathrm{CO}_{2}$ and $\mathrm{CO}$.

$$
A_{i, F I D}=\alpha_{i} A_{i, T C D}
$$

Besides the expressions summarized in Table 3, estimations of the production of water can be made via the hydrogen and oxygen mass balances. For the combustion of methane, the hydrogen from the methane fed to the reactor froms water in stoichiometric proportions. Meanwhile, a mass balance for oxygen follows the stoichiometry of the reactions producing $\mathrm{CO}_{2}, \mathrm{CO}$, and water. Considering a closed mass balance, the ratio of the water production calculated by hydrogen and oxygen $\left(B_{\mathrm{H}_{2} \mathrm{O}}=\right.$ $\left.F_{\mathrm{H}_{2} \mathrm{O}, B_{\mathrm{H}}} / F_{\mathrm{H}_{2} \mathrm{O}, \mathrm{B}_{\mathrm{O}}}\right)$ must equal 1 . Therefore, we wrote $B_{\mathrm{H}_{2} \mathrm{O}}$ for the external and internal standard method using the TCD, TCDFID, and TCD-mehanizer-FID configurations as presented in Eqs. 18-23.

$B_{\mathrm{H}_{2} \mathrm{O}}=\frac{2 \gamma_{\mathrm{CH}_{4}}\left(A_{C \mathrm{CH}_{4}, T C D}^{0}-A_{C H_{4}, T C D}\right)}{2 \gamma_{O_{2}}\left(A_{O_{2}, T C D}^{0}-A_{O_{2}, T C D}\right)-2 \gamma_{C O_{2}} A_{C O_{2}, T C D}-\gamma_{C O} A_{C O, T C D}} \frac{F_{T}}{F_{T}}$

$B_{\mathrm{H}_{2} \mathrm{O}}=\frac{\frac{2 \gamma_{\mathrm{CH}_{4}}}{\alpha_{C_{4}}}\left(A_{C H_{4} F I D}^{0}-A_{C H_{4}, \mathrm{FID}}\right)}{2 \gamma_{O_{2}}\left(A_{O_{2}, T C D}^{0}-A_{O_{2}, T C D}\right)-2 \gamma_{C O_{2}} A_{C O_{2}, T C D}-\gamma_{C O} A_{C O, T C D}} \frac{F_{T}}{F_{T}}$

$B_{\mathrm{H}_{2} \mathrm{O}}=\frac{\frac{2 \gamma_{C \mathrm{H}_{4}}}{\alpha_{C H_{4}}}\left(A_{C H_{4}, \mathrm{FID}}^{0}-A_{C H_{4}, \mathrm{FID}}\right)}{2 \gamma_{O_{2}}\left(A_{O_{2}, T C D}^{0}-A_{O_{2}, T C D}\right)-\frac{2 \gamma_{C O_{2}} A_{C O_{2}, F I D}}{\alpha_{C O_{2}}}-\frac{\gamma_{C O} A_{C O, F I D}}{\alpha_{C O}}} \frac{F_{T}}{F_{T}}$

$B_{\mathrm{H}_{2} \mathrm{O}}=\frac{2 \beta_{C H_{4}}\left(A_{C H_{4}, T C D}^{0}-\omega A_{C H_{4}, T C D}\right)}{2 \beta_{O_{2}}\left(A_{O_{2}, T C D}^{0}-\omega A_{O_{2}, T C D}\right)-2 \omega \beta_{C O_{2}} A_{C O_{2}, T C D}-\omega \beta_{C O} A_{C O, T C D}} \frac{F_{S}}{F_{S}}$

$B_{H_{2} O}=\frac{\frac{2 \beta_{C H_{4}}}{\alpha_{C H_{4}}}\left(A_{C H_{4}, F I D}^{0}-\omega A_{C H_{4}, F I D}\right)}{2 \beta_{O_{2}}\left(A_{O_{2}, T C D}^{0}-\omega A_{O_{2}, T C D}\right)-2 \omega \beta_{C O_{2}} A_{C O_{2}, T C D}-\omega \beta_{C O} A_{C O, T C D}} \frac{F_{S}}{F_{S}}$

$B_{\mathrm{H}_{2} \mathrm{O}}=\frac{\frac{2 \beta_{C_{4}}}{\alpha_{C H_{4}}}\left(A_{C H_{4}, \mathrm{FID}}^{0}-\omega A_{C H_{4}, \mathrm{FID}}\right)}{2 \beta_{O_{2}}\left(A_{O_{2}, \mathrm{TCD}}^{0}-\omega A_{O_{2}, T C D}\right)-\frac{2 \omega \beta_{C O}{ }_{2}{ }_{C O}, \text { FID }}{\alpha_{C O}}-\frac{\omega \beta_{C O} A_{C O, F I D}}{\alpha_{C O}}} \frac{F_{S}}{F_{S}}$ 
Table 3. Equations set to follow the methane combustion reaction in different detection systems, using both the external and the internal standard method.

\begin{tabular}{|c|c|c|c|c|}
\hline \multirow{2}{*}{ Parameter } & \multirow{2}{*}{ Method } & \multicolumn{3}{|c|}{ Detection system } \\
\hline & & TCD & $\begin{array}{l}\text { TCD-FID } \\
\end{array}$ & TCD-Methanizer-FID \\
\hline \multirow{2}{*}{$\begin{array}{l}\text { Conversion } \\
\text { of } \mathrm{CH}_{4}\end{array}$} & External Standard & $X_{C H_{4}}=\frac{A_{C H_{4}, T C D}^{0}-A_{C H_{4}, T C D}}{A_{C H_{4}, T C D}^{0}}$ & \multicolumn{2}{|c|}{$X_{C_{4}}=\frac{A_{C H_{4}, F I D}^{0}-A_{C H_{4}, F I D}}{A_{C H_{4}, F I D}^{0}}$} \\
\hline & Internal Standard & $X_{C H_{4}}=\frac{A_{C H_{4}, T C D}^{0}-A_{C H_{4}, T C D} \omega}{A_{C H_{4}, T C D}^{0}}$ & \multicolumn{2}{|c|}{$X_{C H_{4}}=\frac{A_{C H_{4}, F I D}^{0}-A_{C H_{4}, F I D} \omega}{A_{C H_{4}, F I D}^{0}}$} \\
\hline \multirow{2}{*}{$\begin{array}{l}\text { Conversion } \\
\text { of } \mathrm{O}_{2}\end{array}$} & External Standard & \multicolumn{3}{|c|}{$X_{O_{2}}=\frac{A_{O_{2}, T C D}^{0}-A_{O_{2}, T C D}}{A_{O_{2}, T C D}^{0}}$} \\
\hline & Internal Standard. & \multicolumn{3}{|c|}{$X_{O_{2}}=\frac{A_{O_{2}, T C D}^{0}-A_{O_{2}, T C D} \omega}{A_{O_{2}, T C D}^{0}}$} \\
\hline \multirow{2}{*}{$\begin{array}{l}\text { Selectivity } \\
\text { to } \mathrm{CO}_{2}\end{array}$} & External Standard & $S_{C O_{2}}=\frac{\gamma_{C O_{2}, T C D}}{\gamma_{C H_{4}, T C D}} \frac{A_{C O_{2}, T C D}}{\left(A_{C H_{4}, T C D}^{0}-A_{C H_{4}, T C D}\right)}$ & $S_{C O_{2}}=\frac{\gamma_{C O_{2}, T C D} \alpha_{C H_{4}}}{\gamma_{C H_{4}, T C D}} \frac{A_{C O_{2}, T C D}}{\left(A_{C H_{4}, F I D}^{0}-A_{C H_{4}, F I D}\right)}$ & $S_{C O_{2}}=\frac{\gamma_{C O_{2}, T C D} \alpha_{C H_{4}}}{\gamma_{C H_{4}, T C D} \alpha_{C O_{2}}} \frac{A_{C O_{2}, F I D}}{\left(A_{C H_{4}, F I D}^{0}-A_{C H_{4}, F I D}\right)}$ \\
\hline & Internal Standard & $S_{C O_{2}}=\frac{\beta_{C O_{2}}}{\beta_{C H_{4}}} \frac{A_{C O_{2}, T C D} \omega}{\left(A_{C H_{4}, T C D}^{0}-A_{C H_{4}, T C D} \omega\right)}$ & $S_{C O_{2}}=\frac{\beta_{C O_{2}} \alpha_{C H_{4}}}{\beta_{C H_{4}}} \frac{A_{C O_{2}, T C D} \omega}{\left(A_{C H_{4}, F I D}^{0}-A_{C H_{4}, F I D} \omega\right)}$ & $S_{C O_{2}}=\frac{\beta_{C O_{2}} \alpha_{C H_{4}}}{\beta_{C H_{4}} \alpha_{C O_{2}}} \frac{A_{C O_{2}, F I D} \omega}{\left(A_{C H_{4}, F I D}^{0}-A_{C H_{4}, F I D} \omega\right)}$ \\
\hline \multirow{2}{*}{$\begin{array}{l}\text { Carbon } \\
\text { Mass Ba- } \\
\text { lance }\end{array}$} & External Standard & $B_{C}=\frac{\gamma_{C H_{4}, T C D} A_{C H_{4}, T C D}+\gamma_{C O, T C D} A_{C O, T C D}+\gamma_{C O_{2}, T C D} A_{C O_{2}, T C D}}{\gamma_{C H_{4}} A_{C H_{4}, T C D}^{0}}$ & $B_{C}=\frac{\frac{\gamma_{C H 4, T C D} A_{C H 4, F I D}}{\alpha_{C H 4}}+\gamma_{C O, T C D} A_{C O, T C D}+\gamma_{C O_{2}, T C D} A_{C O_{2}, T C D}}{\frac{\gamma_{C H_{4}} A_{C H_{4}, F I D}^{0}}{\alpha_{C H_{4}}}}$ & $B_{C}=\frac{\frac{\gamma_{C H 4, T C D} A_{C H 4, F I D}}{\alpha_{C H 4}}+\frac{\gamma_{C O, T C D} A_{C O, F I D}}{\alpha_{C O}}+\frac{\gamma_{C O_{2}, T C D} A_{C O_{2}, F I D}}{\alpha_{C O_{2}}}}{\frac{\gamma_{C H_{4}} A_{C H_{4}, F I D}^{0}}{\alpha_{C H_{4}}}}$ \\
\hline & Internal Standard & $B_{C}=\frac{\beta_{C H_{4}, T C D} A_{C H_{4}, T C D}+\beta_{C O, T C D} A_{C O, T C D}+\beta_{C O_{2}, T C D} A_{C O_{2}, T C D}}{\frac{\beta_{C H_{4}} A_{C H_{4}, F I D}^{0}}{\omega}}$ & $B_{C}=\frac{\frac{\beta_{C H 4, T C D} A_{C H 4, F I D}}{\alpha_{C H 4}}+\beta_{C O, T C D} A_{C O, T C D}+\beta_{C O_{2}, T C D} A_{C O_{2}, T C D}}{\frac{\beta_{C H_{4}} A_{C H_{4}, F I D}^{0}}{\omega \alpha_{C H_{4}}}}$ & $B_{C}=\frac{\frac{\beta_{C H 4, T C D} A_{C H 4, F I D}}{\alpha_{C H 4}}+\frac{\beta_{C O, T C D} A_{C O, F I D}}{\alpha_{C O}}+\frac{\beta_{C O_{2}, T C D} A_{C O_{2}, F I D}}{\alpha_{C O_{2}}}}{\frac{\beta_{C H_{4}} A_{C H_{4}, F I D}^{0}}{\omega \alpha_{C H_{4}}}}$ \\
\hline Other & Internal Standard & & $\omega=\frac{A_{N_{2}, T C D}^{0}}{A_{N_{2}, T C D}}$ & \\
\hline
\end{tabular}


Considering the mathematics of the method, the accuracy of the detection systems can be monitored by assessing the closure of the mass balances.

For implementing the analytic method developed above, we made calibration curves for each one of the compounds resulting from the methane combustion reaction. Calibration was made according to the following steps:

i) We prepared four gaseous mixtures of the reaction products and analyzed them with the different configurations of the detection system of the GC. Readings for $\mathrm{CH}_{4}, \mathrm{CO}_{2}$, and $\mathrm{CO}$ were taken from both the FID and the TCD detectors, whereas the readings for $\mathrm{O}_{2}$ and $\mathrm{N}_{2}$ were done with the TCD. Such readings were used to calculate the corresponding areas $A_{i, F I D}$ and/or $A_{i, T C D}$ in the calibration curves.

ii) We calculated $\alpha_{\mathrm{i}}$ values from the slope of plots of $A_{i, F I D}$ vs $A_{i, T C D}$.

iii) For making calculations with the external standard method, we plotted $\frac{F_{i}}{F_{T}}$ vs $A_{i, F I D}$ or $A_{i, T C D}$ and estimated $\gamma_{i, F I D}$ or $\gamma_{i, T C D}$ from the slopes of the produced curves. Notice that, according to the mathematics of the method, $\gamma_{i, T C D}=\alpha_{i} \gamma_{i, F I D}$.

For the internal standard method, the slopes from the curves were obtained after plotting $\frac{F_{i}}{F_{S}}$ vs $\frac{A_{i, F I D}}{A_{S, T C D}}$ and/or $\frac{A_{i, T C D}}{A_{S, T C D}}$ correspond to $\beta_{i, F I D}$ and/or $\beta_{i, T C D}$, respectively. Herein, $\beta_{i, T C D}=\alpha_{i} \beta_{i, F I D}$.

After calibration, the following procedure was implemented for quantifying the composition of the gaseous streams from the catalytic reactor on-line:

i) We injected at least five samples from the reactor feed to the GC and calculated the average $A_{i, F I D}^{0}$ and/or $A_{i, T C D}^{0}$. Periodic injections of samples from the outlet stream of the catalytic reactor were made after starting to run the reaction. Therefore, $A_{i, F I D}$ and/or $A_{i, T C D}$ were calculated as a function of time on stream. We calculated the average $A_{S, T C D}^{0}$ for the internal standard method from the signal for $\mathrm{N}_{2}$.

ii) We calculated the concentration for each compound after replacing the values of $A_{i, F I D}^{0}$ and/or $A_{i, T C D}^{0}, A_{i, F I D}$ and/or $A_{i, T C D}, \gamma_{i, F I D}$ and/or $\gamma_{i, T C D}$, $\beta_{i, F I D}$ and/or $\beta_{i, T C D}$, and $\alpha_{i}$ in the corresponding equations presented in Table 3 .

\section{RESULTS AND DISCUSSION}

\subsection{Assessment of the sensitivity and response factors}

A working hypothesis for our method is that there is a linear correlation between the responses of a given compound in the TCD and FID detectors. Fig. 4 plots the areas calculated for the
FID signals of $\mathrm{CH}_{4}, \mathrm{CO}$, and $\mathrm{CO}_{2}$ as a function of the corresponding areas calculated from the signals of the TCD when different molar flows where injected to the GC. The linearity of the featured curves had $\mathrm{R}^{2} \sim 0.999$ in all instances. This validates our working hypothesis within the concentration ranges for the compounds studied herein, 0.8-7.7 vol \% of $\mathrm{CH}_{4}, \mathrm{CO}_{2}$, and $\mathrm{CO}, 7.7-38.5$ vol. $\%$ of $\mathrm{O}_{2}$, and 46.2-90.8 vol. $\%$ of $\mathrm{N}_{2}$ at a total flow of $130 \mathrm{~mL} \mathrm{~min}^{-1}$ that was kept constant during the calibration procedure. According to our mathematical model, the slopes of these curves are the sensitivity factors of each compound. Table 4 summarizes the calculated sensitivity factors for $\mathrm{CH}_{4}, \mathrm{CO}$, and $\mathrm{CO}_{2}$. To ensure that the accuracy of the sensitivity factors for $\mathrm{CO}$ and $\mathrm{CO}_{2}$ were not affected by the methanizer, we calibrated the $\mathrm{CH}_{4}, \mathrm{CO}_{2}$, and $\mathrm{CO}$ at equivalent molar flows to obtain equivalent FID areas. Fig. 4 shows the results (axis of ordinates). We based our idea on two facts. (1) The stoichiometry factor between methane and $\mathrm{CO}_{2}$ or $\mathrm{CO}$ is 1.0; see Eq. 15-16. (2) Methanation reactions are exothermic and spontaneous (i.e., negative free energy) below $500{ }^{\circ} \mathrm{C}$. Therefore, the criterion of having conversions for both $\mathrm{CO}_{2}$ and $\mathrm{CO}$ around close to $100 \%{ }^{28}$ when using a methanizer was fulfilled and this was further supported by the similarity found for the values of $\gamma_{i, F I D}$ and $\beta_{i, F I D}$ for these molecules, Table 4.

Table 4. Summary of sensitivity and response factors. The $\mathrm{R}^{2}$ for all calibration graphs was greater than 0.998 .

\begin{tabular}{|c|c|c|c|c|c|}
\hline Factor* & $\mathbf{C H}_{\mathbf{4}}$ & $\mathbf{O}_{\mathbf{2}}$ & $\mathbf{N}_{\mathbf{2}}$ & $\mathbf{C O}$ & $\mathbf{C O}_{\mathbf{2}}$ \\
\hline$\alpha_{\mathrm{i}}$ & 1752.6 & - & - & 4863.5 & 5318.9 \\
\hline$\beta_{i, T C D}$ & 0.3631 & 0.7461 & 1.0000 & 1.0543 & 1.0770 \\
\hline$\beta_{i, F I D}\left(\times 10^{3}\right)$ & 0.2072 & & & 0.2168 & 0.2025 \\
\hline$\gamma_{i, T C D}\left(\times 10^{7}\right)$ & 2.8117 & 5.7699 & 7.8273 & 8.1625 & 8.4298 \\
\hline$\gamma_{i, F I D}\left(\times 10^{10}\right)$ & 1.6043 & - & - & 1.6783 & 1.5849 \\
\hline
\end{tabular}

The calibration data also served to calculate the response factors $\beta_{\mathrm{i}}$ and $\gamma_{\mathrm{i}}$ for all the analyzed compounds. The results are also summarized in Table 4. When the response factors were calculated from the areas derived from the TCD, their values decreased in the order: $\mathrm{CH}_{4}<\mathrm{O}_{2}<\mathrm{CO}<\mathrm{CO}_{2}$. This tendency is correlated to the decrease in the difference of thermal conductivities of these gases and argon; namely, 32, 12, 11 and $4 \mathrm{~mW}$ $\mathrm{m}^{-1} \mathrm{~K}^{-1}$ for $\mathrm{CH}_{4}, \mathrm{O}_{2}, \mathrm{CO}$, and $\mathrm{CO}_{2}$, at $160^{\circ} \mathrm{C}$, respectively. The tendencies found for the calibration curves attest for the adequateness of our method.

\subsection{Validation of the developed method}

To validate our method, we quantified the products stream from a catalytic reactor performing the catalytic combustion of methane. Table 3 shows the definitions of conversion, selectivity, and mass balance that we employed. Fig. 5 shows the conversions of $\mathrm{CH}_{4}$ and $\mathrm{O}_{2}$, and the selectivity to $\mathrm{CO}_{2}$ as calculated from the expressions developed for both the FID and the TCD. Fig 5 top shows the results for these catalytic parameters when applying the external standard method while Fig. 5 bottom does the same for the internal standard method. For the external standard method, the trends observed for the conversion of $\mathrm{CH}_{4}$ calculated from the signals of both detectors are the same, but the conversions calculated from the TCD were ca. $1 \%$ lower to 
those calculated from the FID. We also plotted the conversion of $\mathrm{O}_{2}$ calculated from the TCD to corroborate the consistency of the quantification. We observed that both the $\mathrm{CH}_{4}$ and $\mathrm{O}_{2}$ conversions were very similar which is consistent with the stoichiometry of the reaction, Eq. 1, since the reaction feed had a 1:2 $\mathrm{CH}_{4}$ to $\mathrm{O}_{2}$ molar ratio. Concerning the selectivity to $\mathrm{CO}_{2}$, we found values around 1.20 during the experiments, which does not seem to have physical meaning. On the other hand, the results for conversion calculated from the internal standard method, Fig. 5 bottom, were ca. $4 \%$ higher to those found with the external standard method. On the other hand, the curves for the selectivity to $\mathrm{CO}_{2}$ displayed a constant value of 1.00 . Therefore, the internal standard method suppressed the artifact of a selectivity higher than 1.00 . One takeaway message is thus that carefully devised analytical methods are required for drawing meaningful conclusions about the performance of reaction systems when using on-line chromatography.

Fig. 4. Correlation between the FID and TCD areas through the sensitivity factor. $\mathrm{R}^{2}>0.999$. Error bars correspond to t-Student confidence intervals for the mean built with $\alpha=0.05$.

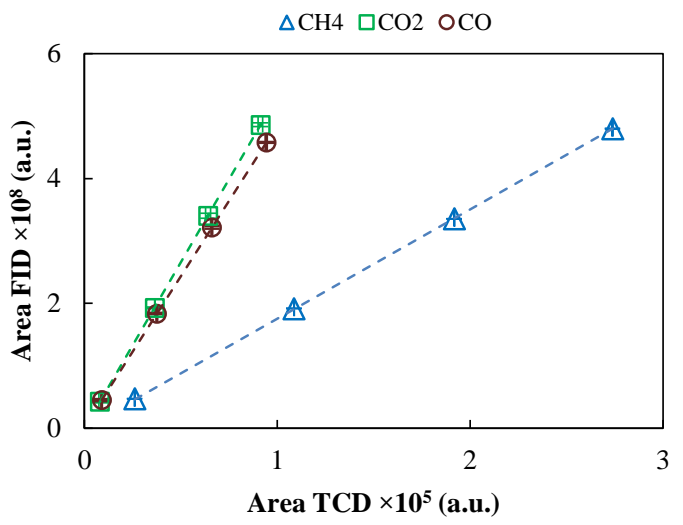

Computing elemental mass balances from the performed quantification is a reliable way of validating the developed methods. However, it is somehow surprising that, as highlighted by Carrero et al. ${ }^{29}$, scores of papers from the catalytic community do not report elemental mass balances. In our case, Fig. 6 shows the evolution of the carbon mass balance in the catalytic system as a function of time on stream. The carbon balances computed from the external standard method showed a decrease from 1.12 to 1.05 , Fig. 6 top. In other words, according to this method, there was more mass leaving the reactor than entering it. And, also, the quantity of mass decreased with time on stream despite maintaining the same mass flow to the system. Somehow, such a result is actually in agreement with the nonrealistic values of selectivity calculated with the external standard method further strengthening the conclusion that this method is unreliable for the kind of analysis developed herein. On the other hand, there was a difference of ca. $2 \%$ between the carbon balance for both detectors. For example, at $2 \mathrm{~h}$ time on stream, the carbon balance value for the FID was 1.07 whereas for the TCD was 1.05. Such a difference is a consequence of the higher sensitivity of the FID. ${ }^{2}$ The accuracy and stability of the carbon mass balance was strongly improved with the internal standard method. Fig. 6 bottom shows that the carbon mass balances calculated from both the TCD and the FID were always closer and not above 1.00 while remaining stable during the duration of the tests. Particularly, the carbon balance calculated from the FID was closer to 1.00 and higher than the one calculated from the TCD. Once again, the accuracy of the FID was superior than the one of the TCD.

Fig. 5. Results of methane and oxygen conversion and selectivity towards $\mathrm{CO}_{2}$ using TCD and FID detectors. The calculations were based on the external (top) and the internal standard (bottom) methods. Error bars correspond to t-Student confidence intervals for the mean built with $\alpha=0.05$.
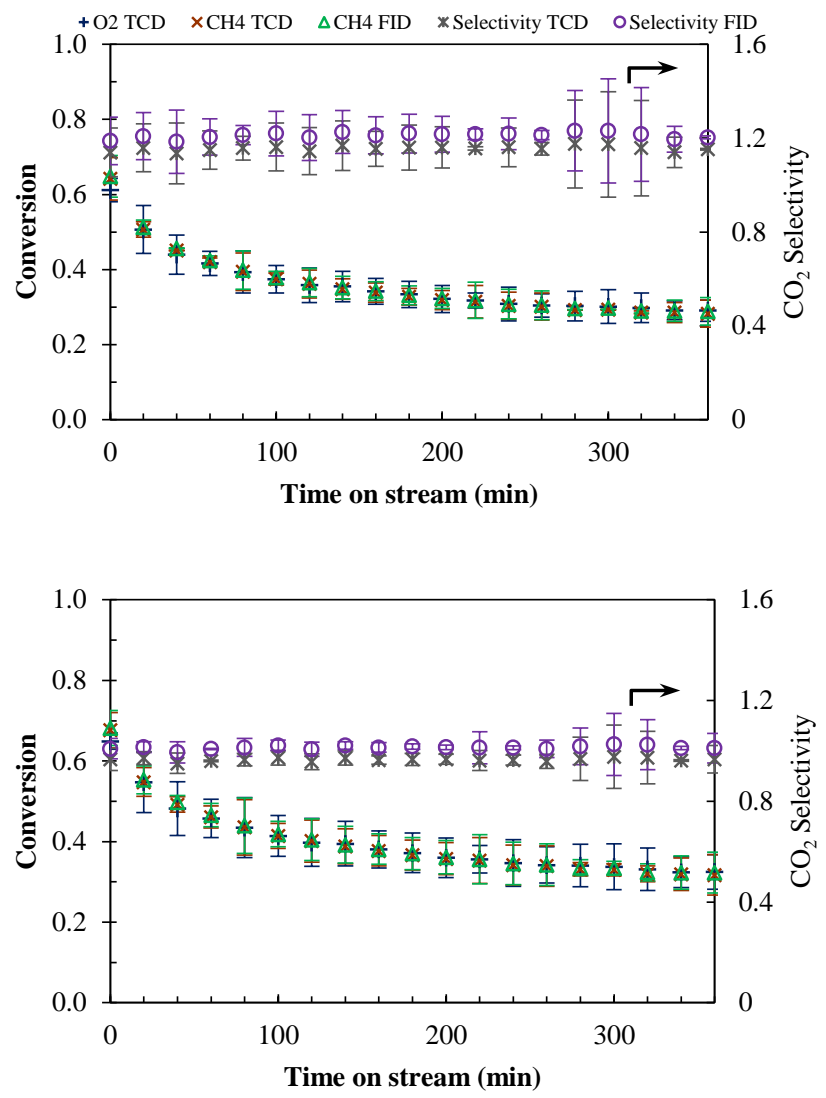

Results in Fig. 6 bottom are consistent with those presented in Fig. 5 bottom, where no changes in selectivity were observed. These results hence validate our method.

Finally, we analyze the calculated molar flows for the products exiting the catalytic reactor. Fig. 7 shows the molar flows of the compounds involved in the reaction calculated from both the external (Fig. 7 top) and the internal (Fig. 7 bottom) standard methods. The results suggest that the external standard method tends to overestimate the molar flows from the reactor due to its inherent limitations. This is the reason why conversions were lower than those of the internal standard method. The calculations from the external standard method did not fulfill the restriction for a constant total molar flow, Fig. 7 top. According to the stoichiometry of Eq. 1, the total number of moles of the products are equal to those of the reactants, so the total molar flow of the system should be constant. However, the calculations from the external standard method indicated that the total molar flow at the inlet of the reactor (i.e., $5.69 \pm 0.10 \mathrm{mmol} \mathrm{min}$ 
$\left.{ }^{1}\right)$ was lower than those estimated in the outlet stream of the reactor during the catalytic experiments. Namely, this method indicated that at the beginning of the reaction, the total molar flow was $6.34 \mathrm{mmol} \mathrm{min}^{-1}$ and decreased during the reaction to 5.98 mmol $\mathrm{min}^{-1}$. This explains the pattern of the carbon balance when this method was applied, Fig 6 top.

Fig. 6. Carbon mass balances using TCD and FID. The calculations were based on methods of external standard (top) and internal standard (bottom). Error bars correspond to t-Student confidence intervals for the mean built with $\alpha=0.05$.
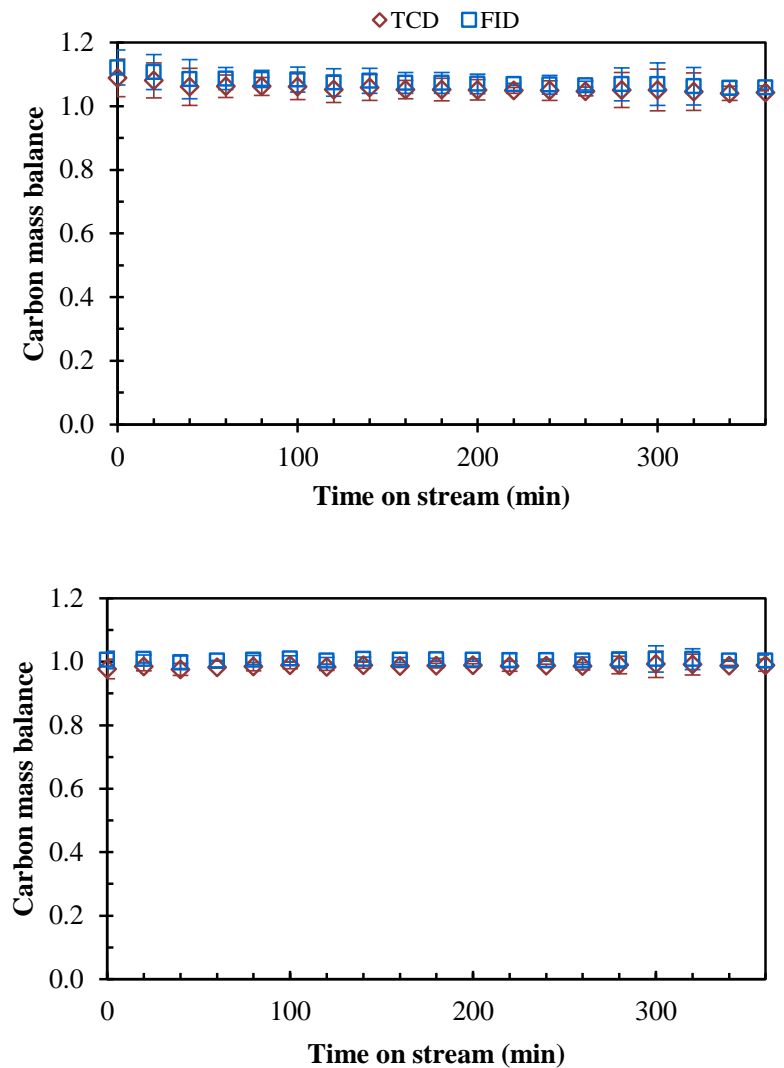

On the other hand, with the internal standard method, the total molar flow during the duration of the tests was constant, at ca. $5.70 \mathrm{mmol} \mathrm{min}^{-1}$, and equal to that of the reaction system inlet. Accordingly, this method produced a physically meaningful closed carbon balance, Fig 6 bottom. For both methods, the ratio of the water production calculated by hydrogen and oxygen $\left(B_{\mathrm{H}_{2} \mathrm{O}}\right)$ was equal to 1.00 , and the molar flow ratio $\mathrm{CO}_{2}$ to water calculated from the hydrogen balance was 2.00, which demonstrates that the calculated value for water production was reasonable.
Fig. 7. The molar flow of the gaseous stream compounds at the outlet of the reactor during a combustion test, calculated by external (top) and internal (bottom) standard method. Error bars correspond to t-Student confidence intervals for the mean built with $\alpha=0.05$.
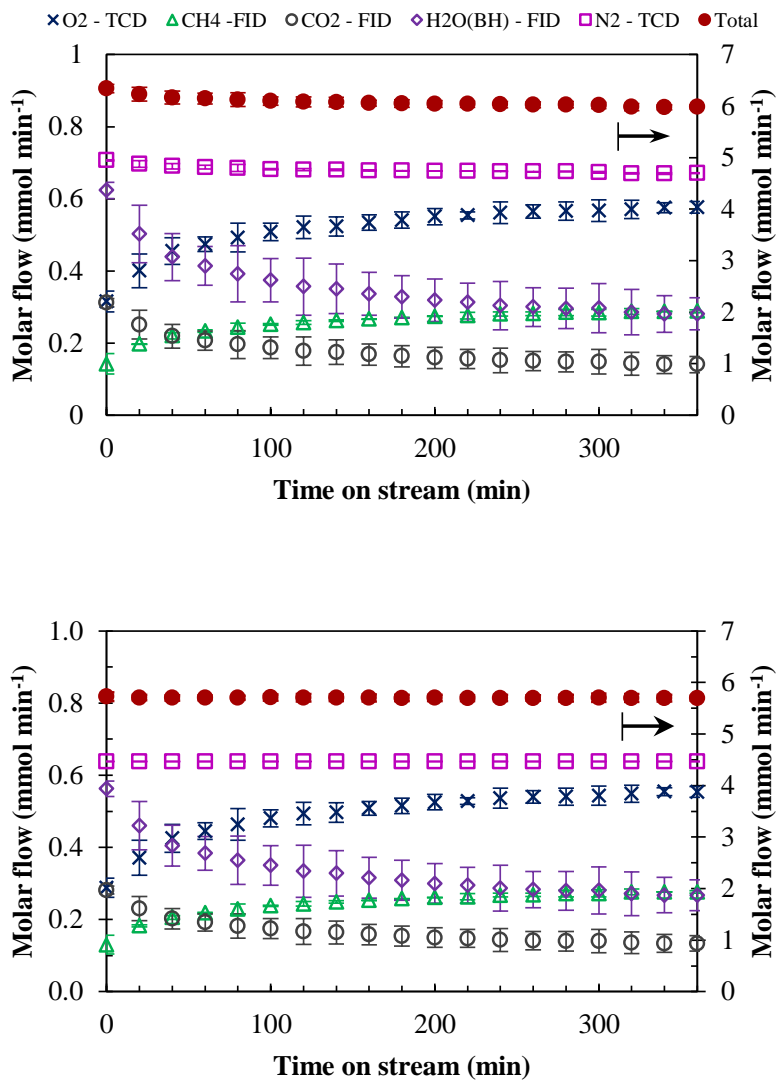

\section{CONCLUSIONS}

We have developed an analytical method for the highly accurate quantification of gaseous streams by on-line chromatography provided with multiple detectors. Particularly, our method considered the use of an on-line gas chromatograph provided with thermal conductivity and flame ionization detectors and a methanizer and applied both the so-called external and internal standard methods of analysis. We found that the external standard method, that actually is the most used by the chemical community, leads to inaccurate quantification which in turn leads to physically meaningless conclusions when applied to the analysis of the gaseous streams in catalytic reaction systems. Conversely, the internal standard method was highly accurate, and its results had physical meaning. These facts are also a call to action from analysts on how crucial it is avoiding oversimplification during gas chromatography for drawing meaningful conclusions in studies that apply the technique for studying diverse gaseous systems. 


\section{ASSOCIATED CONTENT}

\section{Supporting Information}

No additional content is included

\section{AUTHOR INFORMATION}

\author{
Corresponding Author \\ *E-mail: vicbaldo@uis.edu.co
}

\section{Author Contributions}

The manuscript was written through contributions of all authors. / All authors have given approval to the final version of the manuscript.

\section{ACKNOWLEDGEMENTS}

This work was funded by Agencia Nacional de Hidrocarburos ANH- and Minciencias, Colombia within the frame of the Project, 1102-721-50962: "Desarrollo de alternativas catalíticas para la reducción y valorización de emisiones de gases de efecto invernadero típicas de pozos y refinerías petroleras por combustión catalítica de VOCs y transformación de $\mathrm{CO}_{2}$ y $\mathrm{CH}_{4}$ en gas de síntesis".

\section{NOMENCLATURE}

\section{Roman letters}

$A_{i}=$ chromatographic peak area of component $i$

$A_{r}^{0}=$ inlet chromatographic peak area of component $i$

$B_{\mathrm{z}}=\mathrm{z}$ atomic species $(\mathrm{C}, \mathrm{O}$ or $\mathrm{H})$ mass balance

$F_{i}^{0}=$ inlet molar flow rate of component $i, \mathrm{mmol} \mathrm{min}^{-1}$

$F_{i}=$ molar flow rate of component $i, \mathrm{mmol} \mathrm{min}^{-1}$

$F_{T}=$ total molar flow rate, $\mathrm{mmol} \mathrm{min}^{-1}$

$N_{Z, i}=$ number of atoms of $\mathrm{z}$ species in the component $i$

$n_{T}=$ total moles injected to the chromatograph, mol

$P=$ pressure, $\mathrm{kPa}$

$R=$ universal gas constant, $\mathrm{kPa} \mathrm{m}^{3} \mathrm{~mol}^{-1} \mathrm{~K}^{-1}$

$S_{p}=$ selectivity to product $p$

$T=$ temperature, $\mathrm{K}$

$V_{\text {loop }}=$ volume of the injection loop, $\mathrm{m}^{3}$

$X_{r}=$ conversion of reactant $r$

\section{Greek letter}

$\alpha_{i}=$ sensitivity factor of component $i$

$\beta_{i}=$ internal standard response factor of component $i$

$\gamma_{i}=$ external standard response factor of component $i$

$v=$ reactant $r$ to product $p$ reaction stoichiometric factors ratio

\section{Subscripts}

$T C D=$ registered in the thermal conductivity detector

$F I D=$ registered in the flame ionization detector

$i=$ component $i$

$s=$ internal standard

$r=$ reactant

$p=$ product

$T=$ total

\section{Superscripts}

${ }^{\circ}=$ inlet

\section{REFERENCES}

(1) Villalobos, R. J. Chromatogr. Sci. 1990, 28 (7), 341-350.

(2) McNair, Harold M., Miller, James M., Snow, N. H. Basic Gas Chromatography, Third.; Jhon Wiley \& Songs Inc., 219AD.

(3) Kamiński, M.; Kartanowicz, R.; Jastrzębski, D.; Kamiński, M. M. J. Chromatogr. A 2003, 989 (2), 277283.

(4) Andersson, R.; Boutonnet, M.; Järås, S. J. Chromatogr. A 2012, 1247, 134-145.

Drolc, A.; Djinović, P.; Pintar, A. Accredit. Qual. Assur 2013, 18 (3), 225-233.

Jiang, Z.; Yu, J.; Cheng, J.; Xiao, T.; Jones, M. O.; Hao, Z.; Edwards, P. P. Fuel Process. Technol. 2010, 91 (1), 97-102.

(7) Vogt, C.; Kranenborg, J.; Monai, M.; Weckhuysen, B. M. ACS Catal. 2020, 1428-1438.

(8) Singh, R.; Dhir, A.; Mohapatra, S. K.; Mahla, S. K. Biomass Convers. Biorefinery 2019.

(9) Petrov, A. W.; Ferri, D.; Krumeich, F.; Nachtegaal, M.; Van Bokhoven, J. A.; Kröcher, O. Nat. Commun. 2018, 9 (1).

(10) Gancarczyk, A.; Iwaniszyn, M.; Piątek, M.; Korpyś, M.; Sindera, K.; Jodłowski, P. J.; Łojewska, J.; Kołodziej, A. Ind. Eng. Chem. Res. 2018, 57 (31), 10281-10291.

(11) He, L.; Fan, Y.; Bellettre, J.; Yue, J.; Luo, L. Renew. Sustain. Energy Rev. 2020, 119 (October), 109589.

(12) Arora, S.; Prasad, R. RSC Adv. 2016, 6 (110), 108668108688.

(13) Usman, M.; Wan Daud, W. M. A.; Abbas, H. F. Renew. Sustain. Energy Rev. 2015, 45, 710-744.

(14) Ma, R.; Xu, B.; Zhang, X. Catal. Today 2019, 338 (June), $18-30$.

(15) Sun, L.; Wang, Y.; Guan, N.; Li, L. Energy Technol. 2019, 1900826.

(16) $\mathrm{Hu}, \mathrm{Y} . \mathrm{H} . ;$ Ruckenstein, E. In Advances in Catalysis; 2004; Vol. 48, pp 297-345.

(17) Horn, R.; Schlögl, R. Catal. Letters 2015, 145 (1), 23-39.

(18) Yu, Q.; Wang, C.; Li, X.; Li, Z.; Wang, L.; Zhang, Q.; Wu, G.; Li, Z. Fuel 2019, 239 (August 2018), 1240-1245.

(19) Okal, J.; Zawadzki, M.; Baranowska, K. Appl. Catal. B Environ. 2016, 194, 22-31.

(20) Han, Y. F.; Chen, L.; Ramesh, K.; Widjaja, E.; Chilukoti, S.; Kesumawinata Surjami, I.; Chen, J. J. Catal. 2008, 253 (2), 261-268.

(21) Xie, Y.; Zhang, L.; Jiang, Y.; Han, S.; Wang, L.; Meng, X.; Xiao, F.-S. Catal. Today 2019.

(22) Huang, W.; Zha, W.; Zhao, D.; Feng, S. Solid State Sci. 2019, 87, 49-52.

(23) Zhang, Z.; Hu, X.; Zhang, Y.; Sun, L.; Tian, H.; Yang, X. Catal. Sci. Technol. 2019, 9 (22), 6404-6414.

Rezaei, R.; Moradi, G.; Sharifnia, S. Energy \& Fuels 
2019, 33 (7), 6689-6706.

(25) Haber, J. Pure Appl. Chem. 1991, 63 (9), 1227-1246.

(26) Baldovino-Medrano, V. G.; Kartheuser, B.; Gaigneaux, E. M. Catal. Today 2019, 338 (February), 81-92.

(27) Minette, F.; Lugo-Pimentel, M.; Modroukas, D.; Davis, A. W.; Gill, R.; Castaldi, M. J.; De Wilde, J. Appl. Catal. B Environ. 2018, 238 (April), 184-197.

(28) Gao, J.; Wang, Y.; Ping, Y.; Hu, D.; Xu, G.; Gu, F.; Su, F. $R S C A d v$. 2012, 2 (6), 2358.

(29) Carrero, C. A.; Schloegl, R.; Wachs, I. E.; Schomaecker, R. ACS Catal. 2014, 4 (10), 3357-3380. 